\title{
Pituitary Adenylate Cyclase-Activating Peptide in the Bed Nucleus of the Stria Terminalis Mediates Stress-Induced Reinstatement of Cocaine Seeking in Rats
}

\author{
Olivia W Miles*,', Eric A Thrailkill', Anne K Linden², Victor May², Mark E Bouton' and \\ Sayamwong E Hammack' \\ 'Department of Psychological Science, The University of Vermont, Burlington, VT, USA; ${ }^{2}$ Department of Neurological Sciences, The University of \\ Vermont, Burlington, VT, USA
}

\begin{abstract}
Stressors often contribute to difficulties in maintaining behavior change following a period of abstinence, and may play a significant role in drug relapse. The activation of pituitary adenylate cyclase-activating peptide (PACAP) systems in the bed nucleus of the stria terminalis (BNST) mediates many consequences of chronic stressor exposure. Here we ask whether PACAP is also involved in producing reinstatement in a model of stress-induced relapse to drug taking. Rats self-administered cocaine for I h daily over 10 days that was followed by 20 days of extinction training in which lever pressing no longer produced cocaine. In experiment I, quantitative PCR (qPCR) was performed at several stages to determine transcript levels of PACAP and corresponding receptors. Reinstatement of cocaine seeking was then tested after footshock exposure in different groups of rats that were pretreated with vehicle solution, a PACI receptor antagonist (experiment 2), or a PACAP agonist (experiment 3) without footshock. In experiment I, cocaine self-administration increased BNST PACAP transcript levels similar to what we have previously reported with chronic stress. In experiment 2, intra-BNST infusions of the PACINPAC2 antagonist, PACAP 6-38, prevented footshock-induced reinstatement of extinguished cocaine seeking. In experiment 3, intra-BNST PACAP infusion reinstated previously extinguished cocaine-seeking behavior in the absence of footshock. Cocaine self-administration elevated BNST PACAP, and BNST PACAP receptor activation was necessary and sufficient for stress-induced reinstatement of cocaine seeking. These data suggest that BNST PACAP systems may be viable targets for relapse prevention.

Neuropsychopharmacology (2018) 43, 978-986; doi:I0.1038/npp.2017.135; published online 26 July 2017
\end{abstract}

\section{INTRODUCTION}

A primary challenge in the treatment of substance abuse is the tendency of users to relapse following acute or extended periods of abstinence. On average, over $60 \%$ of substance abusers will return to drug use within a year of receiving treatment (Hunt et al, 1971; Scott et al, 2011; Higgins et al, 2012). Although many factors may contribute to drug relapse, one critical factor may be exposure to a stressor (Sinha et al, 2006). That is, relapse rates are higher following stressful events (Breese et al, 2011). Stressors are often studied as sources of relapse in laboratory settings (Shaham et al, 2003), and exposure to stress often reinstates extinguished instrumental responding in animals trained to self-administer cocaine (Mantsch et al, 2015).

Many brain regions implicated in stress- and anxiety-like behavioral responding have also been implicated in the

* Correspondence: OW Miles, Department of Psychological Science, The University of Vermont, 2 Colchester Avenue, Burlington, VT 05405, USA, Tel: +I 802656 I04I, Fax: 802-656-8783, E-mail: omiles@uvm.edu

Received 2 January 20 17; revised 20 May 20 I7; accepted 22 June 2017; accepted article preview online 28 June 2017 stress-induced reinstatement of extinguished drug-reinforced behavior (Koob, 2015). In particular, activation of the bed nucleus of the stria terminalis (BNST) has been argued to mediate anxiety-like behavioral responding to stimuli that signal an aversive event in the intermediate future (eg, in 10 min; Waddell et al, 2006; Hammack et al, 2015), and also mediates stress-induced reinstatement of extinguished drugseeking behavior (Stewart, 2000). Hence, BNST activation can induce the reinstatement of cocaine-seeking behavior (Leri et al, 2002), and BNST lesions (Shaham et al, 2000) attenuate stress-induced reinstatement of drug-reinforced instrumental behavior.

Several stress-related peptides, including corticotropinreleasing hormone $(\mathrm{CRH})$, are expressed in the BNST. The activation of CRH receptors in the BNST is critical for stressinduced reinstatement of extinguished instrumental responding for cocaine: CRH infusions into the BNST, but not central amygdala (CeA) mimic the effects of stressor exposure to reinstate drug seeking in rodents, and BNST CRH receptor antagonism prevents stress-induced reinstatement (Erb and Stewart, 1999). Possible upstream regulators of BNST CRH activation are still unclear. 
Recent studies have implicated pituitary adenylate cyclaseactivating peptide (PACAP) in the regulation of stress responding (Hammack and May, 2015; Stroth et al, 2011), and BNST PACAP activation has been shown to be necessary and sufficient for many of the behavioral consequences of stressor exposure (Hammack et al, 2009; Roman et al, 2014; Kocho-Schellenberg et al, 2014). The pleiotropic PACAP is highly conserved and can exist in two isoforms, with the 38- residue, PACAP38, predominating over PACAP27 in the nervous system. PACAP-positive cell bodies and fibers have been observed in multiple stressrelated regions, including the BNST, where PACAP expression is substantially augmented following chronic stress. Our laboratory and others have argued that PACAP may be upstream of $\mathrm{CRH}$ in both the paraventricular nucleus (PVN; Stroth and Eiden, 2010) and the BNST (Hammack and May, 2015). Indeed, PACAP/PAC1 receptor expression and signaling is highly involved in mediating both physiological and psychological responses to stress (Ressler et al, 2011), as well as stress-related disorders (eg, schizophrenia, posttraumatic stress disorder, and depression; Ressler et al, 2011; Hashimoto et al, 2007; Lehmann et al, 2013). Furthermore, there are high levels of comorbidity between individuals exposed to stress-related disorders and substance abuse (Kessler et al, 1995).

The present experiments addressed this idea by examining the role of PACAP in the BNST in reinstatement of extinguished cocaine-reinforced instrumental behavior occasioned by the presentation of a stressor.

\section{MATERIALS AND METHODS}

\section{Subjects}

Consistent with our work investigating the role of BNST PACAP in stress-related behavior, adult male SpragueDawley rats (experiment 1, $n=40$; experiment 2, $n=27$; experiment 3, $n=29$; 225-250 g upon arrival), obtained from Charles River Laboratories (Canada), were individually housed and received water and rat chow ad libitum (except when specified). After delivery, rats were allowed to habituate to their home cage for 1 week before undergoing surgeries. Rats were maintained on a $12 \mathrm{~h}$ light/dark cycle (lights on at $0700 \mathrm{~h}$ ) and all experimentation occurred with lights on (between 0730 and 1130). All procedures were approved by the institutional animal care and use committee at the University of Vermont.

\section{Apparatus}

One set of four conditioning chambers was used. Each was housed in its own sound-attenuation chamber (Model ENV-008-VP; Med Associates, St Albans, VT). The chambers measured $30.5 \times 24.1 \times 21.0 \mathrm{~cm} \quad$ (length $\times$ width $\times$ height). The floor was made of stainless steel grids $(0.48 \mathrm{~cm}$ diameter $)$. The sidewalls and ceiling were made of clear acrylic plastic, whereas the front and rear walls were made of brushed aluminum. A retractable lever $(4.8 \mathrm{~cm}$ long and positioned $6.2 \mathrm{~cm}$ above the floor grid) was positioned on the right side of the chamber; a nonretractable lever was positioned on the left, and used as a control (inactive) lever. A stimulus light was positioned above each lever, and each chamber was illuminated by a $7.5 \mathrm{~W}$ incandescent bulb mounted to the ceiling of the sound-attenuation chamber, $\sim 35 \mathrm{~cm}$ from the grid floor at the front of the chamber. The operant conditioning chambers were linked to a computer data collection program (MED PC, Med Associates).

\section{Surgical Procedures}

All rats underwent a jugular vein catheter implantation. Rats were anesthetized using isoflurane vapor (1.5-4.0\%) and all surgical procedures were conducted using aseptic techniques. Catheters were constructed using methods described previously (Fuchs et al, 2004) and consisted of external guide cannula with screw-type connectors (Plastic One, Roanoke, VA), silastic tubing $(10 \mathrm{~cm}$; SAI Infusion Technology, Lake Villa, IL), and prolite polypropylene monofilament mesh ( $2 \mathrm{~cm}$ diameter; Biomedical Structures, Warwick, RI). The end of the catheter was inserted into the right jugular vein, secured with suture, and exited on the rat's back, posterior to the shoulder blades. To maintain patency, catheters were flushed once daily for 6 days after surgery with $0.2 \mathrm{ml}$ heparinized saline. For the duration of the experiment, each animal received $0.1 \mathrm{ml}$ heparinized saline directly after each self-administration session to ensure catheter patency.

Immediately following the jugular catheterization, animals in experiments 2 and 3 were implanted with bilateral cannula (22 gauge, Plastics One, Roanoke, VA) aimed at the BNST as previously described (Hammack et al, 2009). Cannula were mounted onto each stereotaxic arm and aimed at an angle of $20^{\circ}$ just dorsal to the oval BNST (from bregma: AP $=-0.1$, $\mathrm{ML}=+3.8, \mathrm{DV}=-5.3$ ). Wire stylettes extending $1 \mathrm{~mm}$ past the tip were inserted into each guide cannula, and cemented in place. Animals received subcutaneous injections of lactated Ringer's solution and an analgesic $(5 \mathrm{mg} / \mathrm{kg}$ Metacam, Boehringer Ingelheim, Vetmedica, St Joseph, MO) administered once immediately after the dual surgery and once the following day. Once awake, rats were returned to their home cages for 7-day postsurgery recovery, during which all rats were observed and weighed daily.

\section{Cocaine Self-Administration}

At 7 days after surgery, all rats were given the opportunity to self-administer cocaine (cocaine hydrochloride $3.0 \mathrm{mg} / \mathrm{ml}$, obtained from PENRO Specialty Compounding, Colchester, VT) during daily $1 \mathrm{~h}$ sessions for 10 days according to a fixed-ratio 1 schedule of reinforcement. At the start of each session, the catheter was connected to a swivel via polyethylene 20 tubing that was encased in steel spring lashes (Plastics One). After the animals were placed in the chamber, a $2 \mathrm{~min}$ period elapsed before the stimulus light came on above the active lever (signaling drug availability). Presses on the active lever resulted in a $0.5 \mathrm{~s}$ cocaine infusion and a $2 \mathrm{~s}$ flashing presentation of the stimulus light above the active lever $(0.5 \mathrm{~s}$ on $/ 0.5 \mathrm{~s}$ off). In an effort to help the animals acquire cocaine-seeking behavior, several manipulations were made during the 10 days of acquisition: all rats received mild food restriction ( $20 \mathrm{~g}$ rat chow per day) on days 1-2. During this period, home cage rat chow was crushed and mixed with water to create a paste that was coated onto the active lever before the self-administration session. On days 3-10, all animals received ad libitum food 
a

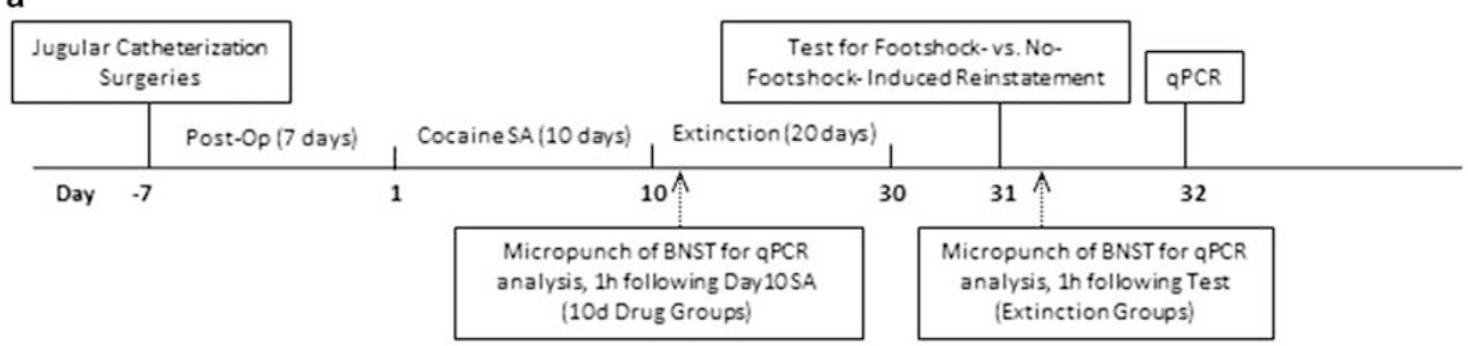

b

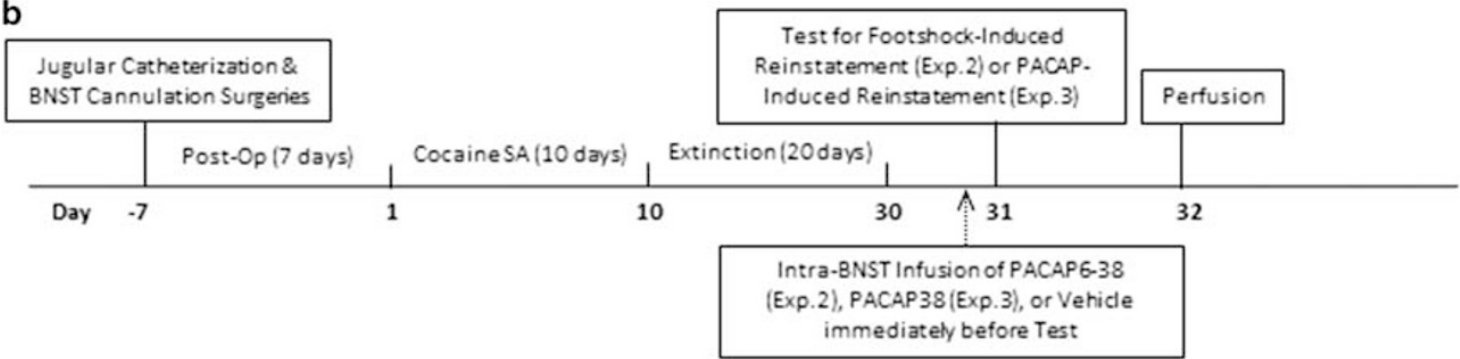

Figure I Experimental timeline for (a) experiment I and (b) experiments 2 and 3.

and water, and the lever was no longer baited. Moreover, the amount of drug delivered per infusion was decreased over the acquisition period to increase cocaine seeking with the following schedule: days $1-3,1.0 \mathrm{mg} / \mathrm{kg} /$ infusion; days $4-7$, $0.75 \mathrm{mg} / \mathrm{kg} /$ infusion; days $8-10,0.50 \mathrm{mg} / \mathrm{kg} /$ infusion.

\section{Extinction}

All rats in experiments 2 and 3, and animals in the Extinction Group of experiment 1 , then received 20 daily sessions in which active lever presses no longer resulted in delivery of cocaine. These extinction sessions lasted $1 \mathrm{~h}$.

\section{Reinstatement}

Experiment 1. Animals in group 10d Drug were killed $1 \mathrm{~h}$ after the last self-administration session (or control treatment, $n=4$; Figure 1a). Brains were rapidly removed and sectioned using a rodent brain matrix (Ted Pella Redding, CA). BNST tissue was then dissected with a brain punch set $(0.96 \mathrm{~mm}$ in diameter; Stoelting, Wood Dale, IL) as depicted in Figure 2a and frozen on dry ice. The remaining experimental rats underwent extinction training, as described above, and following the last extinction session, were placed in the operant conditioning chamber and administered five $2.0 \mathrm{~mA}, 2 \mathrm{~s}$ footshocks (averaging one shock every $12 \mathrm{~min}$ over $1 \mathrm{~h}$; provided by Med Associates (Model ENV-414 shockers)) or no footshock. Active and inactive levers were available throughout the session, but presses had no programmed consequences. At $1 \mathrm{~h}$ after the end of the session, rats were killed and BNST tissue harvested as described above.

Experiment 2. On the day following the last extinction session, rats were split into four groups, counterbalanced for order and time of testing, that received different treatments. Rats were infused into the BNST with $1.0 \mu \mathrm{g}$ PACAP6-38 (American Peptide, Sunnyvale, CA; $0.5 \mu \mathrm{l}$ per side) or equivolume $0.05 \%$ BSA saline vehicle immediately before the test session (between 0730 and $0930 \mathrm{~h}$; Figure 1b) as previously described (Hammack et al, 2009). The $1.0 \mu \mathrm{g}$ dose was chosen based on dose response studies (for review, see Lezak et al, 2014; Roman et al, 2014). Immediately following bilateral infusion, the rat was placed in the operant conditioning chamber and allowed to lever press.

All Shock groups received the same shock treatment as described above. Group Shock-PACAP6-38 received footshock along with a PACAP antagonist infusion; Group Shock-BSA received footshocks and vehicle infusion; Group NoShock-PACAP6-38 received an infusion of the PAC1 antagonist before being reexposed to the operant conditioning chambers on test day; and Group NoShock-BSA received a vehicle infusion and no stressor exposure.

Experiment 3. On the day following the last extinction session, rats were infused into the BNST with $1.0 \mu \mathrm{g}$ PACAP38 ( $n=15$; American Peptide; $0.5 \mu \mathrm{l}$ per side) or equivolume $0.05 \%$ BSA saline vehicle $(n=14)$ immediately before the test session (between 0730 and 0930 h; Figure 1b). Infusions were conducted in the same manner as previously described (Hammack et al, 2009). Active (without cocaine reward delivery) and inactive lever presses were recorded for $1 \mathrm{~h}$.

\section{Quantitative PCR (qPCR) Measures of Transcript Levels}

The qPCR for PACAP and related transcripts was conducted using methods described previously (Girard et al, 2002; Hammack et al, 2009; Missig et al, 2014). Briefly, after killing of rats by rapid decapitation, coronal rat brain sections were prepared using a rodent brain matrix (Ted Pella), and micropunched BNST tissues were frozen for subsequent total RNA extraction using STAT60 RNA/mRNA isolation reagent (Tel-Test ' $\mathrm{B}$ ', Friendswood, TX). All RNAs were reverse transcribed using random hexamer primers with SuperScript II Preamplification System (Invitrogen, Carlsbad, CA). Real-time qPCR was performed as described 
a

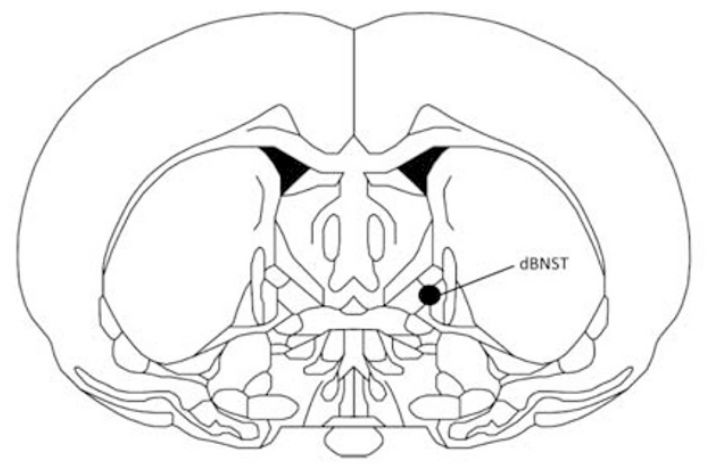

C PACAP Transcript Levels in Cocaine Responders vs. Non-Responders

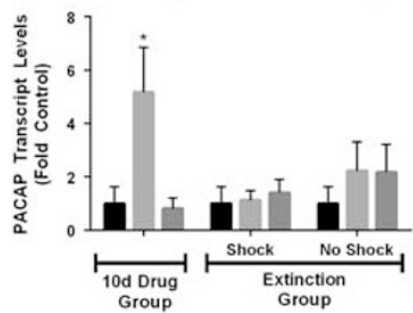

b

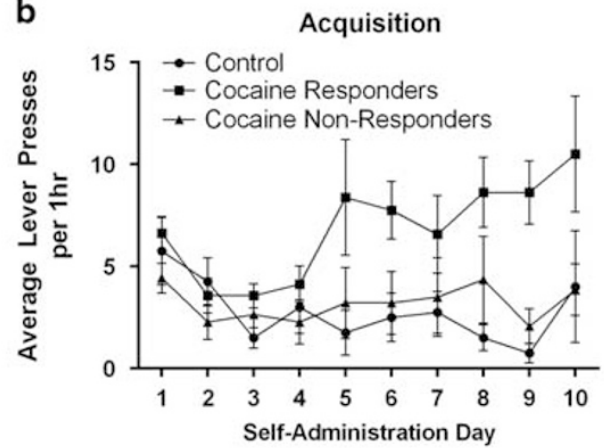

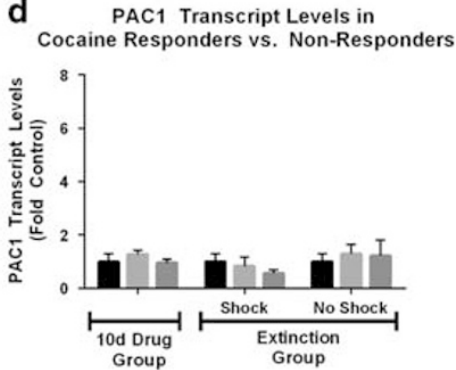

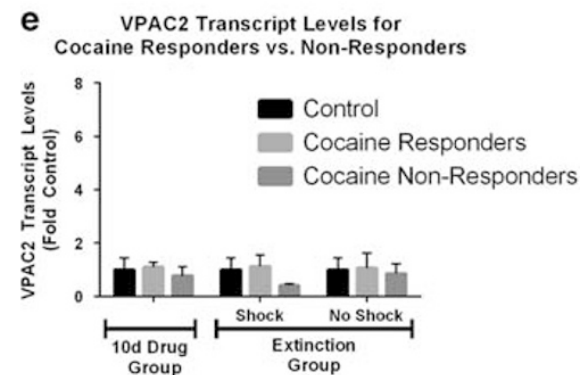

Figure 2 Cocaine self-administration alters endogenous PACAP levels in the BNST. Adult male rats self-administered cocaine for I0d as described, and several underwent 20d extinction training. dBNST was harvested for quantitative PCR analyses after IOd of self-administration (Group I0d Drug), or after selfadministration and then 20d Extinction Training (Group Extinction). All tissue samples were reverse transcribed with random hexamers to allow quantification

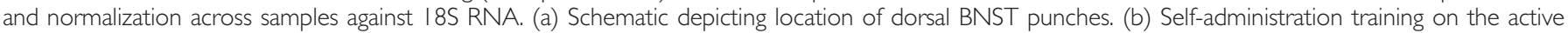
lever; inactive lever presses remained uniformly low throughout acquisition (data not shown). (c) The IOd cocaine self-administration increases PACAP in

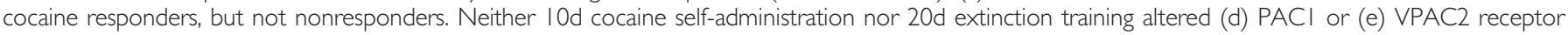
transcript in cocaine responders and nonresponders in dBNST. Data from 40 animals were used in the analyses of transcript levels during different phases of

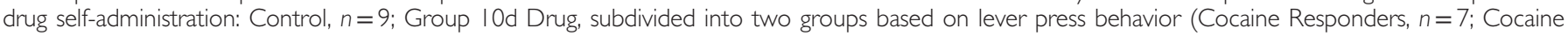
Nonresponders, $n=8$; Group Extinction, subdivided into four groups based on lever press behavior and counterbalanced shock treatment; Extinction-Shock-

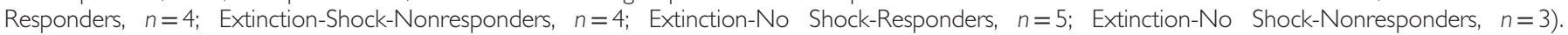

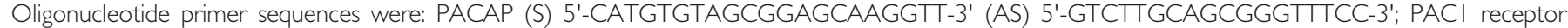

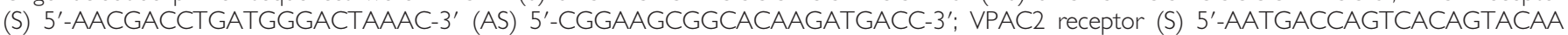

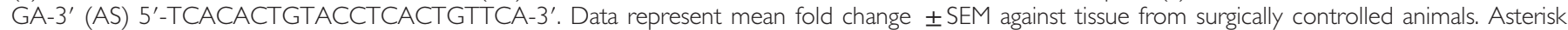
indicates significantly different at $p<0.05$.

previously using SYBR Green I detection (Girard et al, 2002; Hammack et al, 2009; Missig et al, 2014) and cDNA templates were treated with $\mathrm{RNase} \mathrm{H}$ to remove residual RNA, then diluted 10 -fold to minimize potential inhibitory effects of the reverse transcription reaction. Melting profiles for amplified DNA fragments were performed to verify unique product amplification in the $\mathrm{qPCR}$ analysis, and a standard curve was constructed by amplification of serially diluted plasmids containing the target sequence (Girard et al, 2002; Missig et al, 2014). Transcript levels in each sample were calculated from the threshold cycle (CT), and determined by the SYBR Green I fluorescence intensity $(\Delta \mathrm{Rn})$ at specific amplification cycles. For each target sequence, all samples from the same brain regions were amplified together in the same assay to minimize variability. All data were normalized to $18 \mathrm{~S}$ RNA levels.

\section{Histology}

In experiments 2 and 3, rats were anesthetized 1 day after reinstatement testing with Beuthanasia-D (sodium pentobarbital; Zoetis, Kalamazoo, MI) solution and perfused transcardially with $200 \mathrm{ml}$ saline $(0.9 \%)$ with $0.1 \%$ heparin (Sagent, Schaumburg, IL) followed by $100 \mathrm{ml}$ of $10 \%$ formalin solution (Fisher Scientific, Atlanta, GA). Brain tissues were postfixed at $4{ }^{\circ} \mathrm{C}$ for a minimum of $24 \mathrm{~h}$ in $10 \%$ formalin. Fixed tissue was then cut using a cryostat, and sections were collected at $60 \mu \mathrm{m}$ thickness. Sections were dry mounted, stained with cresyl violet stain, and coverslipped. Cannula placements were visualized using a $4 \times$ Nikon Objective on an Olympus microscope.

\section{Data Analysis}

Statistical analysis was completed using SPSS Version 21 software (IBM Software, Armonk, NY) and graphical representations were completed using GraphPad version 6 (GraphPad Software, San Diego, CA). Lever press responding during each phase of the experiment was analyzed using repeated measure ANOVAs. Two-way ANOVA was used to calculate overall group differences and interactions followed by Bonferroni post hoc test; where indicated, some comparisons between groups were completed using $t$-tests.

\section{RESULTS}

\section{Experiment 1}

Experiment 1 was designed to determine whether 10 days of cocaine self-administration training elevated BNST PACAP 


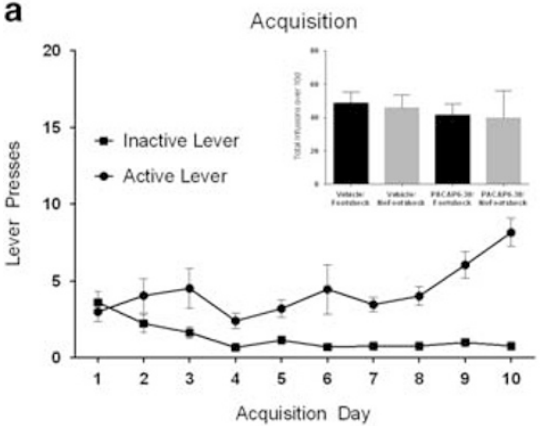

b

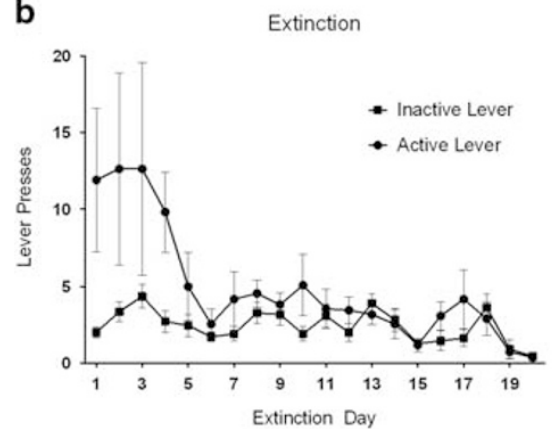

C

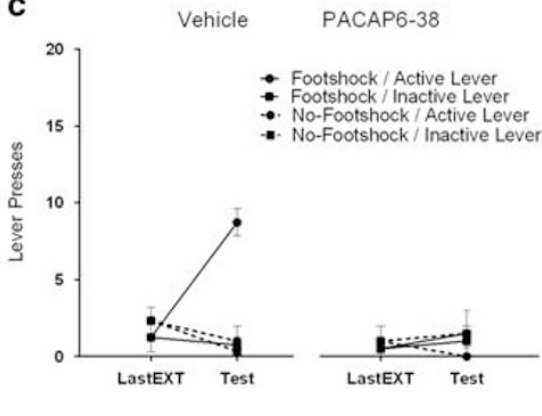

Figure 3 Intra-BNST PACAP antagonist (PACAP6-38) attenuates stress-induced reinstatement in rats. (a) Self-administration during experiment 2. Animals in both footshock/no-footshock and vehicle/antagonist groups received the same amount of cocaine during acquisition (inset). (b) Extinction training during experiment 2. (c) To determine whether PACAP receptor activation during footshock is necessary for stress-induced reinstatement of cocaine-seeking behavior, we infused the PACINPAC2 antagonist PACAP6-38 into the BNST during the test phase of the stress-induced reinstatement procedure. Intra-BNST PACAP6-38 attenuates stress-induced reinstatement when delivered before intermittent footshock. Intra-BNST delivery of the PACAP antagonist significantly attenuated shock-induced reinstatement. Only animals that received intra-BNST vehicle treatment before footshock demonstrated reinstatement of extinguished drug-seeking behavior. Group Shock-PACAP6-38, $n=9$; Shock-BSA, $n=6$; NoShock-PACAP6-38, $n=6$; NoShock-BSA, $n=6$. Data represent mean lever presses \pm SEM.

transcripts, similar to what we have previously reported with chronic stressor exposure (Hammack et al, 2009), and whether BNST PACAP transcripts are also elevated by subsequent stressor (shock) exposure. A median split analysis for total lever presses over $10 \mathrm{~d}$ was used to separate cocaine responders $(M=49.80, S D=7.81)$ from cocaine nonresponders $(\mathrm{M}=14.5, \mathrm{SD}=3.11)$. A median split analysis was also conducted on control animals, but no differences in lever press behavior were found, and hence control animals were grouped together for subsequent comparative analyses. Lever pressing during acquisition is summarized in Figure 2b. A one-way ANOVA on the PACAP mRNA transcript levels revealed a significant difference among the groups $(F(6,24)=5.478, p<0.05)$. The $10 \mathrm{~d}$ cocaine selfadministration increased PACAP mRNA transcript levels approximately fivefold $(p<0.05)$ in the dorsal aspect of the anterolateral BNST (dBNST, Figure 2c) in cocaineresponding animals compared with controls and cocaine nonresponding animals. Importantly, the increase in PACAP expression appears to be a result of chronic (10d) cocaine self-administration, as acute cocaine exposure (1d) did not alter PACAP expression compared with control, $t(20)=0.756$, NS (Supplementary Figure 1). To assess whether these changes were associated with increased receptor mRNA levels, the same cDNA templates were assayed for PAC1 and VPAC2 receptor expression. PAC1 and VPAC2 transcript levels did not differ in the same samples (Figure $2 \mathrm{~d}$ and e). Interestingly, subsequent analyses revealed that chronic cocaine administration did not alter corticotropin-releasing hormone $(\mathrm{CRH} ; \mathrm{F}(6,24)=1.707$, NS) or vasoactive intestinal peptide (VIP; $\mathrm{F}(6,24)=0.414, \mathrm{NS}$ ) transcript levels in the dBNST. Moreover, there were no differences in any transcript levels of animals that underwent extinction training or received footshock $v s$ no footshock on test day. This indicates that BNST PACAP transcripts return to control level after $20 \mathrm{~d}$ of extinction of cocaine seeking.

\section{Experiment 2}

In experiment 1 , we found that 10 days of cocaine selfadministration significantly elevated BNST PACAP transcript levels; however, these levels were not significantly elevated following extinction treatment with or without footshock exposure. Notably, PACAP mRNA levels may not reflect the amount of mature peptide released in response to an acute stressor exposure, and footshock may lead to a release of BNST PACAP that is not reflected in changes in PACAP transcripts. In experiment 2, in order to determine whether PACAP receptor activation during footshock is necessary for stress-induced reinstatement of cocaineseeking behavior, we infused the PAC1/VPAC2 antagonist PACAP6-38 into the BNST during the test phase of the stress-induced reinstatement procedure. Figure 5 a shows the distribution of cannulae placements in analyzed animals.

As in experiment 1, animals responded almost solely on the active lever that produced cocaine delivery; hence, active and inactive lever presses differed by the end of acquisition (Figure $3 \mathrm{a}$ ). By the end of extinction, all rats had reached $\leqslant 5$ responses (Figure 3b). Inactive lever responses remained uniformly low throughout extinction. The mean $( \pm$ SEM) number of responses made on the active and inactive levers on the last day of extinction and during the test for reinstatement is shown in Figure 3c.

A repeated measures ANOVA for inactive lever press responses did not reveal significant effects. Regarding active lever presses, there was a significant main effect of session between the last day of extinction and testing $(\mathrm{F}(1,23)=9.47$, $p<0.01)$. There were also significant interactions between session and shock $(\mathrm{F}(1,23)=14.031, p<0.01)$ and session and infusion treatment $(\mathrm{F}(1,23)=7.89, p<0.05)$. Finally, there was a significant session by shock by infusion treatment interaction $(\mathrm{F}(1,23)=12.10, p<0.01)$, consistent with the fact that only animals that received the footshock and vehicle infusion demonstrated stress-induced reinstatement. Importantly, animals in both the vehicle and PACAP6-38 groups received the same amount of cocaine during acquisition (Figure 3a, inset), indicating that reinstatement was elicited by footshock exposure rather than total cocaine intake during acquisition. PACAP6-38 blocked reinstatement of extinguished cocaine seeking when the rats were exposed to a shock stressor. The post hoc analyses comparing antagonist and vehicle infusion on total responses on the active lever 

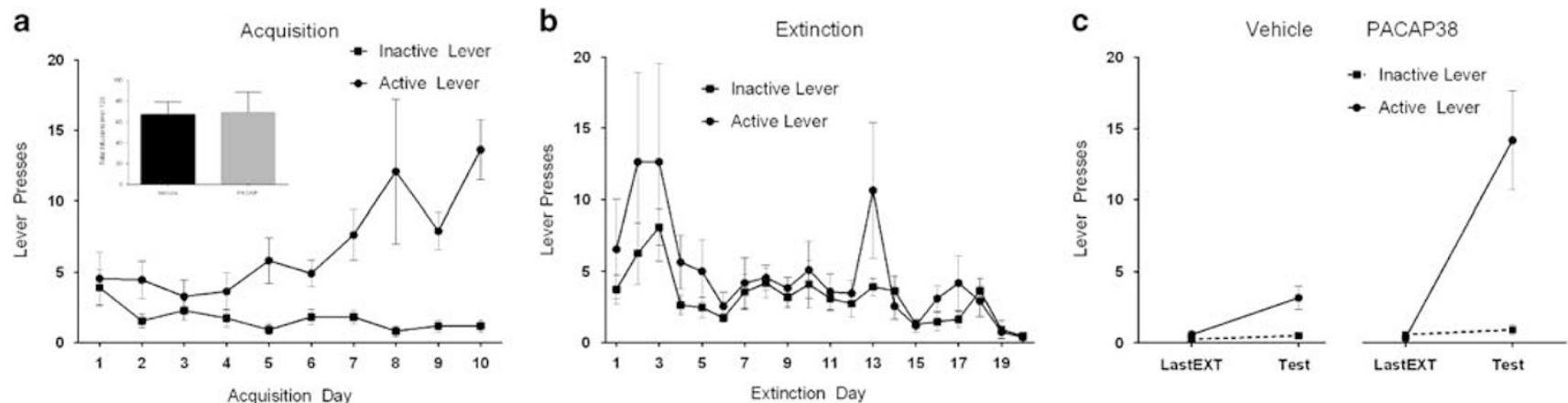

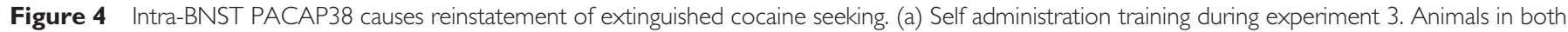

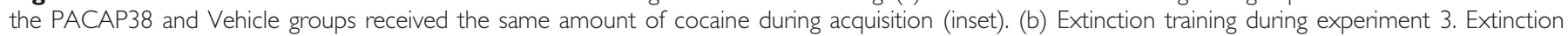

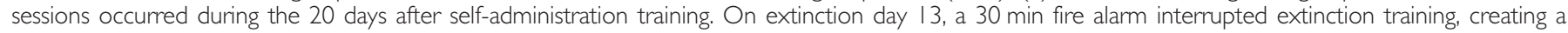

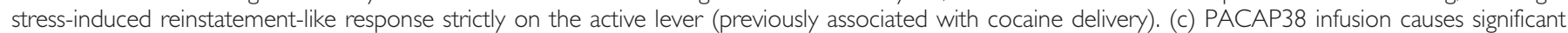

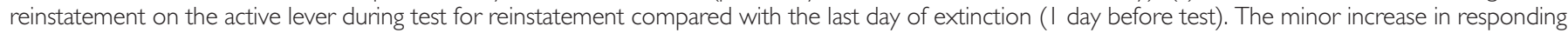
by vehicle could be because of the stress of infusion; $p>0.05$. Vehicle BSA Group, $n=14 ;$ PACAP38 Group, $n=15$.

after footshock exposure revealed significantly less responding in the PACAP6-38 condition $(p<0.01)$. In addition, the number of responses on the active lever in the no-footshock condition after injections of PACAP6-38 did not differ from lever press activity after vehicle infusion (see Figure $3 \mathrm{c}$ ). The PAC1 receptor antagonist did not alter responding on the inactive lever $(\mathrm{F}(1,23)=2.3, \mathrm{NS})$ and responses remained low (0-3 lever presses) during testing.

\section{Experiment 3}

Experiments 1 and 2 determined that cocaine selfadministration elevates BNST PACAP, and that BNST PACAP receptor activation is necessary for stress-induced reinstatement of extinguished cocaine-seeking behavior. Experiment 3 was therefore designed to determine whether BNST PACAP infusion is also sufficient to induce cocaineseeking behavior in the absence of stressor exposure. Figure $5 \mathrm{~b}$ shows the distribution of cannula placements in analyzed animals.

As usual, rats increased their active-lever responding across sessions of acquisition (Figure 4a). This is supported by an ANOVA indicating reliably greater active than inactive lever presses in the final session of acquisition $(F(2,17)$ $=2.52, p<0.05)$. Both PACAP38 and vehicle groups received the same amount of cocaine during acquisition (Figure $4 \mathrm{a}$, inset).

The mean $( \pm$ SEM) number of responses made on the active and inactive levers during the extinction session is shown in Figure $4 \mathrm{~b}$. All rats reached $\leqslant 5$ responses by the final session of extinction. Inactive lever responses remained uniformly low throughout extinction. In contrast to the otherwise consistent decrease in lever pressing over extinction, on extinction day 13, a 30 min fire alarm interrupted 4 animals during the extinction session (Figure 4b; day 13). This interruption produced a noticeable increase solely on active lever press responses.

The results of the reinstatement test are shown in Figure 4c. Bilateral intra-BNST infusion of PACAP agonist, PACAP38, significantly increased active lever responding in the test session. Only rats that received PACAP38 increased responding on the active lever during the test for reinstatement, although a slight, insignificant increase can be seen on the active lever in animals that received vehicle treatment that likely resulted from the mild stress of infusion. No significant differences in responding were found between animals infused with BSA vehicle solution. A treatment (PACAP38, BSA) by session (Last Extinction, Test) ANOVA supported these observations. There was significant effect of session $(\mathrm{F}(1,27)=12.08, p<0.01)$ and a session by treatment interaction $(\mathrm{F}(1,27)=9.25, p<0.01)$. The post hoc analyses comparing agonist and vehicle infusion on total responses on the active lever after footshock exposure revealed significantly more responding in the PACAP38 condition $(p<0.01)$. The PACAP agonist did not alter responding on the inactive lever, and responses on the inactive lever remained uniformly low during testing.

\section{DISCUSSION}

Ten days of cocaine self-administration significantly elevated BNST PACAP transcript levels, although PAC1, CRH, VIP, and VPAC2 transcript levels were unchanged. In contrast, BNST PACAP transcript levels were not elevated by the reinstatement footshock treatment; however, as noted above, footshock may lead to peptide release that is not reflected in changes in mRNA. Our laboratory has previously demonstrated a change in both PACAP transcript and PACAP immunostaining in the dorsal aspect of the anterolateral BNST following chronic stress, but changes in protein following chronic cocaine exposure remain unknown. Consistent with a role for active PACAP during reinstatement testing, infusion of PAC1/VPAC2 receptor antagonist, PACAP6-38, immediately before footshock exposure prevented the footshock from reinstating extinguished cocaine seeking, thus suggesting that BNST PAC1/VPAC2 receptor activation is necessary for stress-induced reinstatement of the response. In experiment 3, infusion of $1.0 \mu \mathrm{g}$ PACAP38 into the BNST was also sufficient to cause reinstatement of extinguished cocaine-seeking behavior in the absence of footshock. These results are consistent with hypotheses suggesting that stress systems have a role in the vulnerability to relapse following stressor exposure (Koob and Le Moal, 2008). The current experiments suggest that BNST PACAP 

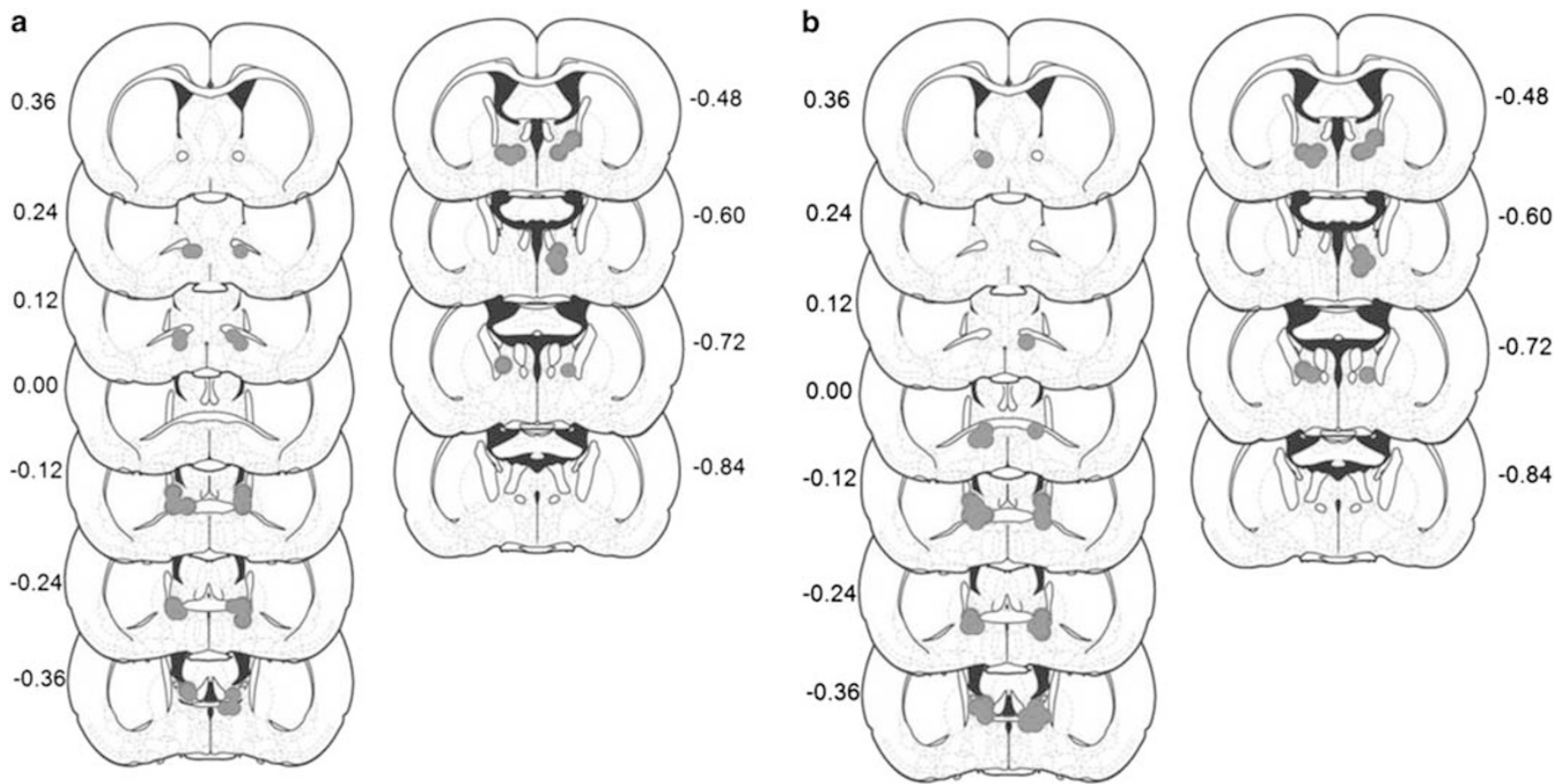

Figure 5 BNST cannula placements. (a) Cannula placements for experiment 2 and (b) experiment 3 are depicted above such that enclosed red dots represent a I mm extension beyond the tip of the cannula. Rats were included in the analysis if their placement resided with a portion of the BNST. In experiments 2 and 3, animals that failed to learn the lever press behavior were removed from the study, and thus only animals that consistently selfadministered cocaine were tested for reinstatement. Furthermore, rats were eliminated from analysis for BNST cannulation experiments if cannulae placement fell outside the histological boundary of the BNST, fell within the lateral ventricles, or if animals did not complete behavioral testing (experiment 2, $n=1$; experiment $3, n=4)$. A full color version of this figure is available at the Neuropsychopharmacology journal online.

activation may be critical for regulating extinguished drug seeking following stressor exposure.

PACAP effects can be mediated by three receptor subtypes; PAC1 receptors bind with high affinity to PACAP, whereas VPAC1/VPAC2 receptors bind with equal affinities to both PACAP and VIP (Harmar et al, 2012). PAC1 receptor activation can lead to the activation of several intracellular signaling cascades, including adenylate cyclase (AC) and phospholipase C (PLC), depending on the PAC1 receptor isoform activated. The resulting activation can subsequently result in heightened membrane depolarization, neurotransmitter release, and action potential firing (Harmar et al, 2012; Spongier et al, 1993; Braas and May, 1999). Also activated are pathways important for neurodevelopment and neuroplasticity following stressor exposure, such as the extracellular signal-related kinase (ERK) and phosphoinositide 3-kinase (PI-3) pathways. Furthermore, PACAP/PAC1 dysregulation may participate in the development of physiological disorders, such as anxiety and depression (Hammack and May, 2015; Hashimoto et al, 2010). The BNST PACAP receptor subtype(s) mediating the reinstatement of cocaine-seeking behavior by stress are unknown; however, we have previously reported that chronic stress upregulated BNST PAC1 receptor transcripts, but not BNST VPAC1/VPAC2 transcripts (Lezak et al, 2014; Hammack et al, 2009). Moreover, many of the consequences of stressor exposure can be mimicked by infusion of the PAC1 receptor agonist maxadilan in the BNST; hence, it is likely that the stress-like effects of BNST PACAP activation are mediated by PAC1 receptors. In the present experiments, PACAP6-38 exerts antagonist actions at both PAC1 and VPAC2 receptors; although this does not rule out VPAC2 activation, the efficacy of PACAP6-38 is consistent with prior data suggesting BNST PAC1 receptor signaling mediates the consequences of stressor exposure (Hammack et al, 2009; Roman et al, 2014; Ressler et al, 2011).

The BNST has been argued to play a key role in an antireward system that may be upregulated by repeated administration of drugs of abuse (Koob and Le Moal, 2008; 2001). Stressor exposure may promote relapse by activating some of the same anti-reward circuits associated with withdrawal (Koob, 2015). The activation of central CRH systems has been suggested as a key step in the recruitment of this antireward system by drugs of abuse (Koob and Le Moal, 2005), as PACAP may be an upstream regulator of CRH in several stress-related regions such as the BNST. The present data thus suggest that BNST PACAP recruitment might also be a key feature of the antireward system that sustains addiction and promotes relapse. Interestingly, we did not observe an increase in BNST CRH transcripts following chronic cocaine self-administration. Upstream PACAP release could enhance the excitability of BNST CRH neurons to promote CRH release independent of changes in transcript, but it may also be possible that BNST PACAP targets a specific population of CRH neurons (Marcinkiewcz et al, 2016).

Key to the negative reinforcement view of addiction described above is the fact that drugs of abuse simultaneously activate both brain reward circuits and antireward (stress) systems that are negative in value. As a result, the activation of central and peripheral stress responses likely becomes a part of the context of drug taking. Stress might therefore create a 'renewal effect', and cause a relapse of responding 
when it occurs again after extinction has been conducted in the absence of stress (see, eg, Bouton, 2014). BNST PACAP activation may be a critical component of drug administration that becomes a part of the context of drug taking that can then produce renewal following extinction. Consistent with this argument, cocaine has been shown to activate neurons in the BNST (Singewald et al, 2003), and, as shown here, BNST transcript levels are significantly increased by cocaine selfadministration. Hence, BNST PACAP activation may represent part of the context of cocaine self-administration that serves to renew cocaine-seeking behavior after extinction.

BNST activity is required for stress-induced reinstatement of drug-seeking behavior. Lesion studies have suggested BNST CRH innervation from the CeA (Sakanaka et al, 1986) and CRH infusion directly into the BNST results in cocaine reinstatement that mimics stress-induced reinstatement, an effect blocked by intra-BNST administration of CRH antagonists (Erb and Stewart, 1999; Wang et al, 2006). Prior reports have suggested that activation of $\mathrm{CRH}$ receptors in the BNST, but not the amygdala, mediates stress-induced reinstatement to drug seeking (Erb and Stewart, 1999). At the circuit level, CRH release regulates BNST synaptic activity, both directly and via interactions with noradrenergic systems (Kash and Winder, 2006; Nobis et al, 2011). The role of BNST CRH and norepinephrine in processes related to addiction is complex and may depend on the drug investigated, and it is still unclear how and whether BNST PACAP interacts with these other BNST systems to produce the behavioral effects observed in this report. As noted above, we and others have argued that PACAP is upstream of BNST CRH activation and thus may be critical in mediating the effects of stress on the reinstatement of extinguished drug-seeking behaviors.

Several studies have reported that during human abstinence from drug use, stress exposure often occurs in the presence of contextual cues that had previously been associated with drug use (Epstein et al, 2009); these cues alone may cause a renewal of responding after abstinence. In addition, in a similar manner to the drug cue-induced reinstatement mentioned above, human studies have indicated that stressor exposure can lead to cue-induced drug craving (Mantsch et al, 2015; Moran-Santa Maria et al, 2015; Fox et al, 2014). Furthermore, Sinha et al (1999) and Sinha (2001) reported a clinical trial based on the rodent stressinduced reinstatement paradigm. In these trials, stressor exposure (guided imagery stress and Trier Social Stress Task) caused increased drug craving. In addition, researchers provided a systemic CRH injection to induce physiological (ie, increased cortisol release) and psychological (ie, increased anxiety) stress responses. Since then, many researchers have examined the effects of different drugs on stressinduced relapse (Moran-Santa Maria et al, 2015; Sinha et al, 2007; Fox et al, 2012; McKee et al, 2014), but none have observed the potential effect of PACAP on stress-induced relapse. PACAP treatments may locally target BNST PAC1/ VPAC2 receptors via systemic injection in an effort to antagonize receptors and prevent PACAP binding that facilitates stress responses and, subsequently, stress-induced relapse to drug seeking. By blocking BNST PACAP activation, PVN CRH activity may be modified, altering responses to stressor exposure. Continued research of mechanisms that underlie stress- and drug cue-induced reinstatement after a period of abstinence may lead to the development of viable treatments for relapse prevention.

\section{FUNDING AND DISCLOSURE}

The authors declare no conflict of interest.

\section{ACKNOWLEDGMENTS}

This work was supported in part by National Institutes of Health grants MH-97988 (to SEH/VM), DA033123 (to $\mathrm{MEB})$, the Neuroscience, Behavioral and Health Initiative from the University of Vermont, and UVM College of Arts and Sciences. Portions of the work were also supported by funds from the Center of Biomedical Research Excellence (COBRE) in Neuroscience at the University of Vermont (National Institute of Health NIGMS P30 GM103498/NCRR P30 RR032135). We thank Micaela O'Reilly, John Treffalls, and Douglas Vormstein-Schneider for technical assistance.

\section{REFERENCES}

Bouton ME (2014). Why behavior change is difficult to sustain. Prev Med 68: 29-36.

Braas KM, May V (1999). Pituitary adenylate cyclase-activating polypeptides directly stimulate sympathetic neuron neuropeptide $\mathrm{Y}$ release through $\mathrm{PAC1}$ receptor isoform activation of specific intracellular signaling pathways. J Biol Chem 274: 27702-27710.

Breese GR, Sinha R, Heilig M (2011). Chronic alcohol neuroadaptation and stress contribute to susceptibility for alcohol craving and relapse. Pharmacol Ther 129: 149-171.

Epstein DH, Willner-Reid J, Vahabzadeh M, Mezghanni M, Lin JL, Preston KL (2009). Real-time electronic diary reports of cue exposure and mood in the hours before cocaine and heroin craving and use. Arch Gen Psychiatry 66: 88-94.

Erb S, Stewart J (1999). A role for the bed nucleus of the stria terminalis, but not the amygdala, in the effects of corticotropinreleasing factor on stress-induced reinstatement of cocaine seeking. J Neurosci 19: RC35-1.

Fox HC, Morgan PT, Sinha R (2014). Sex differences in guanfacine effects on drug craving and stress arousal in cocaine-dependent individuals. Neuropsychopharmacology 39: 1527-1537.

Fox HC, Seo D, Tuit K, Hansen J, Kimmerling A, Morgan PT et al (2012). Guanfacine effects on stress, drug craving and prefrontal activation in cocaine dependent individuals: preliminary findings. J Psychopharmacol 26: 958-972.

Fuchs RA, Evans KA, Parker MP, See RE (2004). Differential involvement of orbitofrontal cortex subregions in conditioned cue-induced and cocaine-primed reinstatement of cocaine seeking in rats. $J$ Neurosci 24: 6600-6610.

Girard BM, May V, Bora SH, Fina F, Braas KM (2002). Regulation of neurotrophic peptide expression in sympathetic neurons: quantitative analysis using radioimmunoassay and real-time quantitative polymerase chain reaction. Regul Pept 109: 89-101.

Hammack SE, May V (2015). Pituitary adenylate cyclase activating polypeptide in stress-related disorders: data convergence from animal and human studies. Biol Psychiatry 78: 167-177.

Hammack SE, Todd TP, Kocho-Schellenberg M, Bouton ME (2015). Role of the bed nucleus of the stria terminalis in the acquisition of contextual fear at long or short context-shock intervals. Behav Neurosc 129: 673-678.

Hammack SE, Cheung J, Rhodes KM, Schutz KC, Falls WA, Braas KM et al (2009). Chronic stress increases pituitary adenylate cyclase-activating peptide (PACAP) and brain-derived neurotrophic factor (BDNF) mRNA expression in the bed 
nucleus of the stria terminalis (BNST): roles for PACAP in anxiety-like behavior. Psychoneuroendocrinology 34: 833-843.

Harmar AJ, Fahrenkrug J, Gozes I, Laburthe M, May V, Pisegna JR et al (2012). Pharmacology and functions of receptors for vasoactive intestinal peptide and pituitary adenylate cyclase-activating polypeptide: IUPHAR Review 1. Br J Pharmacol 166: 4-17.

Hashimoto R, Hashimoto H, Shintani N, Chiba S, Hattori S, Okada T et al (2007). Pituitary adenylate cyclase-activating polypeptide is associated with schizophrenia. Mol Psychiatry 12: 1026-1032.

Hashimoto R, Hashimoto H, Shintani N, Ohi K, Hori H, Saitoh O et al (2010). Possible association between the pituitary adenylate cyclase-activating polypeptide (PACAP) gene and major depressive disorder. Neurosci Lett 468: 300-302.

Higgins ST, Silverman K, Sigmon SC, Naito NA (2012). Incentives and health: an introduction. Prev Med 55: S2.

Hunt WA, Barnett LW, Branch LG (1971). Relapse rates in addiction programs. J Clin Psychology 27: 455-456.

Kash TL, Winder DG (2006). Neuropeptide Y and corticotropinreleasing factor bi-directionally modulate inhibitory synaptic transmission in the bed nucleus of the stria terminalis. Neuropharmacology 51: 1013-1022.

Kessler RC, Sonnega A, Bromet E, Hughes M, Nelson CB (1995). Posttraumatic stress disorder in the National Comorbidity Survey. Arch Gen Psychiatry 52: 1048-1060.

Kocho-Schellenberg M, Lezak KR, Harris OM, Roelke E, Gick N, Choi I et al (2014). PACAP in the BNST produces anorexia and weight loss in male and female rats. Neuropsychopharmacology 39: $1614-1623$.

Koob GF (2013). Addiction is a reward deficit and stress surfeit disorder. Frontiers in Psychiatry 4: 72.

Koob GF, Le Moal M (2001). Drug addiction, dysregulation of reward, and allostasis. Neuropsychopharmacology 24: 97-129.

Koob GF, Le Moal M (2005). Plasticity of reward neurocircuitry and the 'dark side' of drug addiction. Nat Neurosci 8: 1442-1444.

Koob GF, Le Moal M (2008). Addiction and the brain antireward system. Annu Rev Psychol 59: 29-53.

Lehmann ML, Mustafa T, Eiden AM, Herkenham M, Eiden LE (2013). PACAP-deficient mice show attenuated corticosterone secretion and fail to develop depressive behavior during chronic social defeat stress. Psychoneuroendocrinology 38: 702-715.

Leri F, Flores J, Rodaros D, Stewart J (2002). Blockade of stressinduced but not cocaine-induced reinstatement by infusion of noradrenergic antagonists into the bed nucleus of the stria terminalis or the central nucleus of the amygdala. J Neurosci 22: 5713-5718.

Lezak KR, Roman CW, Braas KM, Schutz KC, Falls WA, Schulkin J et al (2014). Regulation of bed nucleus of the stria terminalis PACAP expression by stress and corticosterone. J Mol Neurosci 54: 477-484.

Mantsch JR, Baker DA, Funk D, Lê AD, Shaham Y (2015). Stressinduced reinstatement of drug seeking: 20 years of progress. Neuropsychopharmacology 41: 335-356.

Marcinkiewcz CA, Mazzone CM, D’Agostino G, Halladay LR, Hardaway JA, DiBerto JF et al (2016). Serotonin engages an anxiety and fear-promoting circuit in the extended amygdala. Nature 537: 97-101.

McKee SA, Potenza MN, Kober H, Sofuoglu M, Arnsten AF, Picciotto MR et al (2014). A translational investigation targeting stress-reactivity and prefrontal cognitive control with guanfacine for smoking cessation. J Psychopharmacol 29: 300-311.

Missig G, Roman CW, Vizzard MA, Braas KM, Hammack SE, May V (2014). Parabrachial nucleus (PBn) pituitary adenylate cyclase activating polypeptide (PACAP) signaling in the amygdala: implication for the sensory and behavioral effects of pain. Neuropharmacology 86: 38-48.
Moran-Santa Maria MM, Baker NL, Ramakrishnan V, Brady KT, McRae-Clark A (2015). Impact of acute guanfacine administration on stress and cue reactivity in cocaine-dependent individuals. Am J Drug Alcohol Abuse 41: 146-152.

Nobis WP, Kash TL, Silberman Y, Winder DG (2011). B-Adrenergic receptors enhance excitatory transmission in the bed nucleus of the stria terminalis through a corticotropinreleasing factor receptor-dependent and cocaine-regulated mechanism. Biol Psychiatry 69: 1083-1090.

Ressler KJ, Mercer KB, Bradley B, Jovanovic T, Mahan A, Kerley K et al (2011). Post-traumatic stress disorder is associated with PACAP and the PAC1 receptor. Nature 470: 492-497.

Roman CW, Lezak KR, Hartsock MJ, Falls WA, Braas KM, Howard AB et al (2014). PAC1 receptor antagonism in the bed nucleus of the stria terminalis (BNST) attenuates the endocrine and behavioral consequences of chronic stress. Psychoneuroendocrinology 47: 151-165.

Sakanaka M, Shibasaki T, Lederis K (1986). Distribution and efferent projections of corticotropin-releasing factor-like immunoreactivity in the rat amygdaloid complex. Brain Res 382: 213-238.

Scott CK, Dennis ML, Laudet A, Funk RR, Simeone RS (2011). Surviving drug addiction: the effect of treatment and abstinence on mortality. Am J Public Health 101: 737-744.

Shaham Y, Erb S, Stewart J (2000). Stress-induced relapse to heroin and cocaine seeking in rats: a review. Brain Res Rev 33: 13-33.

Shaham Y, Shalev U, Lu L, de Wit H, Stewart J (2003). The reinstatement model of drug relapse: history, methodology and major findings. Psychopharmacology 168: 3-20.

Singewald N, Salchner P, Sharp T (2003). Induction of c-Fos expression in specific areas of the fear circuitry in rat forebrain by anxiogenic drugs. Biol Psychiatry 53: 275-283.

Sinha R (2001). How does stress increase risk of drug abuse and relapse? Psychopharmacology 158: 343-359.

Sinha R, Catapano D, O'Malley S (1999). Stress-induced craving and stress response in cocaine dependent individuals. Psychopharmacology 142: 343-351.

Sinha R, Garcia M, Paliwal P, Kreek MJ, Rounsaville BJ (2006). Stress-induced cocaine craving and hypothalamic-pituitaryadrenal responses are predictive of cocaine relapse outcomes. Arch Gen Psychiatry 63: 324-331.

Sinha R, Sinha R, Li CSR, Sinha R, Li CSR (2007). Imaging stressand cue-induced drug and alcohol craving: association with relapse and clinical implications. Drug Alcohol Rev 26: 25-31.

Spongier D, Waeber C, Pantaloni C, Holsboer F, Bockaert J, Seeburgt PH et al (1993). Differential signal transduction by five splice variants of the PACAP receptor. Nature 365: 170-175.

Stewart J (2000). Pathways to relapse: the neurobiology of drug-and stress-induced relapse to drug-taking. J Psychiatry Neurosci 25: 125.

Stroth N, Eiden LE (2010). Stress hormone synthesis in mouse hypothalamus and adrenal gland triggered by restraint is dependent on pituitary adenylate cyclase-activating polypeptide signaling. Neuroscience 165: 1025-1030.

Stroth N, Holighaus Y, Ait-Ali D, Eiden LE (2011). PACAP: a master regulator of neuroendocrine stress circuits and the cellular stress response. Ann NY Acad Sci 1220: 49-59.

Waddell J, Morris RW, Bouton ME (2006). Effects of bed nucleus of the stria terminalis lesions on conditioned anxiety: aversive conditioning with long-duration conditional stimuli and reinstatement of extinguished fear. Behav Neurosci 120: 324.

Wang J, Fang Q, Liu Z, Lu L (2006). Region-specific effects of brain corticotropin-releasing factor receptor type 1 blockade on footshock-stress-or drug-priming-induced reinstatement of morphine conditioned place preference in rats. Psychopharmacology 185: 19-28.

Supplementary Information accompanies the paper on the Neuropsychopharmacology website (http://www.nature.com/npp)

Neuropsychopharmacology 